\title{
Gerenciamento de resultados e a relação com o custo da dívida das empresas brasileiras abertas ${ }^{1}$
}

\section{Earnings management and the relation with cost of debt of Brazilian public companies}

Paula Carolina Ciampaglia Nardi ${ }^{2}$

Professora dos Departamentos de Ciências Contábeis e de Administração do Centro Universitário COC • E-mail: paula.nardi@yahoo.com.br Silvio Hiroshi Nakao

Professor Doutor do Departamento de Contabilidade da Faculdade de Economia, Administração e Contabilidade de Ribeirão Preto da Universidade de São Paulo•E-mail: shnakao@usp.br

Recebido em $12.05 .2009 \cdot$ Aceito em $16.07 .2009 \cdot 2^{a}$ versão aceita em 17.07 .2009

\section{RESUMO}

Sob a teoria de agência e as premissas de gerenciamento de resultados, o objetivo do trabalho foi estudar a relação entre o gerenciamento de resultados (GR) e o custo da dívida (Ki) das empresas brasileiras abertas, no período de 1996 a 2007. Os pressupostos levantados, por meio da literatura existente, são de que, almejando melhores condições contratuais, como o custo da dívida, o custo atual ou paśsado motiva a empresa a gerenciar o resultado corrente para obter melhores condições de custo futuro ou corrente. Dessa forma, as empresas, intencionalmente, procurariam gerenciar seus resultados, motivadas pelo custo da dívida. Todavia, há apoio teórico para que a relação entre essas variáveis seja unidirecional, com o GR influenciando o custo da dívida, sustentando a segunda hipótese. Para chegar ao objetivo, o trabalho utilizou, como proxy de GR, o modelo para cálculo dos accruals discricionários proposto por Kang e Sivaramakrishnan (1995). As análises foram baseadas no teste não-paramétrico U de Mann-Whitney, seguidas do teste de especificação de Hausman para a análise de simultaneidade, finalizando com a regressão com dados dispostos em painel com correção de Newey-West. Os testes de média apontaram para uma relação positiva entre GR e Ki, mas o teste de simultaneidade não indicou haver inter-relação entre as variáveis. Contudo, os resultados das regressões em painel indicaram que o Ki não influencia o GR, mas que há uma relação positiva, em que quanto maior o GR, maior o custo da dívida, ou seja, este é influenciado por aquele.

Palavras-chave: Gerenciamento de Resultados. Accruals Discricionários. Custo da Dívida.

\section{ABSTRACT}

Under agency theory and assumptions of earnings management, the objective is to study the relationship between earnings management (EM) and the cost of debt (Ki) of Brazilian publicly held companies in the period from 1996 to 2007. The assumptions raised through the literature are that targeting better contractual terms, like cost of debt, current or past cost, motivates the company to manage the current result so as to obtain better conditions for current or future cost. Thus, companies, intentionally, would seek to manage their results, motivated by the cost of debt. However, theoretical support for the relationship between these variables would be unidirectional, with EM influencing the cost of debt, supporting the second hypothesis. To reach the objective, the work used the EM model for the discretionary accruals proposed by Kang and Sivaramakrishnan (1995) as a proxy. The tests were based on Mann-Whitney's $₫$ nonparametric U test, followed by the Hausman specification test for simultaneity analysis, ending with regression with panel data arranged with NeweyWest correction. Tests showed the average for a positive relationship between EM and Ki, but the test did not

Artigo apresentado no $33^{\circ}$ EnANPAD, São Paulo-SP, 2009

Artigo fruto da dissertação defendida pela autora na Faculdade de Economia, Administração e Contabilidade de Ribeirão Preto da Universidade de São Paulo 
indicate that there is a simultaneous inter-relationship between variables. The results of the panel regression indicates that Ki does not influence EM, but there is a positive relationship between them, in which the higher the EM, the higher the Ki.

Keywords: Earnings Management. Discretionary Accruals. Cost of Debt.

\section{INTRODUÇÃO}

Por meio da teoria de agência, sabe-se que as pessoas buscam alcançar interesses próprios e que, apesar da existência dos contratos entre as partes, eles não conseguem abranger todas as possíveis atitudes oportunistas que um agente pode vir a ter em detrimento da riqueza do principal. Isso ocorre porque existe uma assimetria informacional entre o agente e o principal, logo, este fica mais seguro quando é bem informado, quando tem informações confiáveis e transparentes. Assim, quanto maior a qualidade nas informações, tanto menor a assimetria de informações, reduzindo a incerteza do usuário, acarretando decisões econômicas mais eficientes. Contudo, quando se têm poucas e duvidosas informações, o principal pode sentir-se em um contexto de maior insegurança, em posição arriscada, o que o induz a elevar o prêmio pelo risco, conhecido como prêmio pelo risco da falta de informação. Nesse sentido, a contabilidade pode auxiliar os usuários na tomada de decisão e tem a função de reduzir a assimetria informacional, minimizar os conflitos de interesses e contribuir para uma alocação de recursos adequada, como destaca Paulo (2007, p. 10). Mas nas empresas, há pessoas com necessidades e incentivos distintos, as quais podem usar a liberdade permitida em lei para atingir interesses singulares. Desse modo, segundo Lopes e Martins (2005), a possibilidade de exercer discricionariedade permite aos administradores liberdade na mensuração do resultado da empresa, o que é conhecido como "Gerenciamento de Resultados" (GR). Nesse ponto, pesquisas verificaram que certas escolhas são feitas para iludir os usuários quanto ao real desempenho econômico-fi- nanceiro da empresa por meio de GR, o qual seria fruto de uma atitude oportunista. Mas se tal fato é possível, pode-se verificar que o objetivo de reduzir a assimetria informacional e contribuir para alocação de recursos mais segura, por parte da contabilidade, pode não ser alcançado conforme se esperava.

O GR é possível, pois há liberdade na norma contábil que permite ao gestor exercer discricionariedade diante dos procedimentos contábeis. Quando o administrador escolhe "o quê", "como" ou "quando" divulgar uma informação, ele pode impactar no resultado da empresa, de forma a reduzir a qualidade da transparência dessa informação. Apesar disso, há duas linhas de pensamento quanto ao objetivo de gerenciar resultados: a) o GR pode ser uma boa maneira de a empresa divulgar sua realidade econômico-financeira, em vez de simplesmente adotar as mesmas escolhas contábeis para eventos semelhantes, segundo Lopes e Martins (2005) e b) como mencionado por Schipper (1989) e Healy e Whalen (1999), o GR é um ato oportunista, em que o agente atua para atingir seus interesses em detrimento da geração de riqueza para o principal.

Além das definições, existem motivações, destacadas na literatura (FIELD; LYS; VINCENT, 2001; HEALY; WHALEN, 1999; HOLTHAUSEN; LEFTWHICH, 1983; LOPES; MARTINS, 2005; MARTINEZ, 2001; WATTS; ZIMMERMAN, 1990), para as empresas gerenciarem seus resultados, como a motivação para atender às restrições contratuais de empréstimos impostas com a finalidade de facilitar ou melhorar as condições de empréstimos futuros, ou seja, a empresa, diante de custos altos da dívida, pode ser motivada a geren- 
ciar os resultados na tentativa obter melhores custos. Por outro lado, se o GR for percebido pelas fontes de financiamentos como maneira de iludi-los quanto ao desempenho econômico-financeiro da empresa, tais fontes podem elevar o prêmio pelo risco cobrado no financiamento (quanto maior o risco, maior será o retorno exigido). Por conseguinte, maiores serão os custos de captação para as empresas.

Nesse contexto, estudos encontram evidência de que, no Brasil, as empresas fazem GR, como os de Martinez (2001) e Decourt, Martinewski e Pietro Neto (2007). Apesar disso, poucos estudos exploraram a relação entre GR e o custo da dívida.

Por outro lado, pesquisas internacionais (CALEGARI; 2000, FRANCIS et al., 2002; 2005) vêm focando essa relação e, como resultado, tais estudos encontraram uma relação positiva entre GR e o custo de capital de terceiros: quanto maior o GR das companhias, maiores são seus custos de captação.

Porém, tais resultados foram obtidos no mercado norte-americano. Assim sendo, não é evidente que tais resultados se repitam para países com diferenças nos sistemas legal e financeiro, com particularidades sociais, econômicas e culturais, como o Brasil. Desse modo, surge o interesse em examinar, no contexto das empresas brasileiras, como se dá a relação entre o custo da dívida e o GR, se há uma inter-relação ou uma relação unidirecional entre eles (se o custo da dívida é influenciado pelo GR, como observado por Francis et al. (2002 e 2005) e Boubakri e Ghouma (2008) ou se é o contrário).

O fato é que a contabilidade, ao fornecer informação ao mercado, exerce um papel importante na administração de conflitos de interesses e na redução da assimetria informacional, de modo que um dos resultados esperados seja a redução no custo de capital. Afinal, de acordo com Easley e O'Hara (2001), a informação contábil mais precisa reduz o risco do investidor, sugerindo haver uma relação entre a qualidade da informação disponibilizada e o retorno exigido pelos fornecedores de recursos à empresa.

Portanto, diante do exposto anteriormente, parece interessante averiguar se há uma relação entre o retorno exigido pelos credores, diante da possibilidade de as empresas brasileiras estarem gerenciando resultados, e como se dá essa relação.

Assim, surge a questão de pesquisa: qual a relação entre o gerenciamento de resultados contábeis e o custo das dívidas das companhias abertas brasileiras?

O objetivo geral da presente pesquisa é contribuir com o conhecimento a respeito do relacionamento entre custo de dívida e gerenciamento de resultados, mais especificamente sobre a inter-relação (ou relação bidirecional, em que o GR influencia o custo da dívida e esse, por sua vez impacta no GR das empresas) e a relação unidirecional (em que o custo da dívida é influenciado pelo GR), por meio do exame das informações das empresas brasileiras abertas.

A pesquisa relaciona-se com um tema que vem sendo cada vez mais desenvolvido e publicado nos periódicos internacionais, sendo de crescente interesse pelos acadêmicos nacionais, tanto sob o ponto de vista teórico quanto sob a observação empírica. Dessa forma, esta pesquisa contribui para expandir as pesquisas existentes sobre gerenciamento de resultados, além de procurar colaborar na identificação de sua possível inter-relação com o custo da dívida das empresas brasileiras abertas. A análise das inter-relações entre as variáveis é uma lacuna nos trabalhos já desenvolvidos sobre GR.

\section{REFERENCIAL TEÓRICO}

2.1 Teoria de Agência

$\mathrm{Na}$ “Teoria da Agência”, desenvolvida por
Jensen e Meckling (1976), há decisões que podem maximizar a riqueza de uma par- 
te e as que maximizam o interesse da outra, de modo que decisões favoráveis a um lado podem ser desfavoráveis ao outro, porque há propósitos imperfeitamente simétricos e custos de oportunismo (aqueles provenientes de comportamento oportuno) e de controle. Essa teoria está pautada na inexistência de agente perfeito e de contrato completo e na existência de assimetria de informações.

Dessa forma, considerando a contabilidade um sistema de informações, pode-se dizer que ela tem a capacidade de permitir que seus usuários (investidor/credor) conheçam a realidade econômica e financeira da empresa e terem bases sólidas para fazerem análises e tomarem decisões quanto à alocação de recursos. Contudo, a informação deve transparecer a verdadeira realidade da companhia, permitindo maior simetria informacional entre a empresa e os diversos usuários. Cumprindo esse objetivo de bem informar, é possível dizer que a contabilidade desempenha um papel importante na redução dos conflitos de interesses, mediante a minimização da assimetria de informações.

Sobre o aspecto de informar, Sunder (1997, p. 20) destaca que a contabilidade deve informar os participantes a respeito do grau de sucesso no cumprimento dos contratos; distribuir informação para os potenciais participantes em contratos com a empresa para reduzir o custo da negociação dos contratos. Contudo, na contabilidade, mais propriamente nas normas contábeis, é possível que o administrador opte por critérios contábeis ao longo do tempo, exercendo certa discricionariedade, que pode ser resultado de um ato oportunista, capaz de impactar na qualidade e transparência das informações contábeis, elevando a assimetria para com os usuários externos e não minimizando os conflitos de agência, conforme esperado pelos objetivos da contabilidade. Assim, de acordo com Lopes e Martins (2005, p. 55), a contabilidade pode ser usada com a finalidade de realizar uma comunicação seletiva de aspectos mais interessantes do comportamento da empresa. Essa comunicação é seletiva porque os gestores podem selecionar as informações mais convenientes aos seus interesses. Os autores ainda afirmam que “... os administradores podem manipular as informações, fornecendo números com o objetivo de iludir os usuários a respeito da 'real' situação da empresa'.

\subsection{Resultado Contábil, Discricionariedade e Oportunismo}

Dentro do processo de informação da contabilidade, segundo Martinez (2001, p. 1), o resultado é uma das informações mais importantes aos usuários. De acordo com Sunder (1997, p. 67), o resultado contém informações valiosas sobre a continuidade e viabilidade da empresa, sendo que nenhuma outra estatística contábil conduz informações importantes para tantos agentes diferentes. Sobre a importância do resultado aos usuários, Colauto e Beuren (2004, p. 2) consideram que ele possa ser um parâmetro, em se tratando de política de investimento, pois interfere no processo de tomada de decisão dos investidores e credores, nas decisões de investimento dos administradores, entre outros fatores, pois segundo Hendrinksen e Van Breda (1999, p. 174-205), o lucro é usado para a predição da trajetória futura da empresa e como medida de desempenho e orientação para decisões gerenciais futuras, para predizer lucros futuros, para avaliar o risco de investir na empresa ou mesmo para emprestar dinheiro. Diante da importância do resultado contábil, Coelho (2007, p. 50) destaca que a percepção de um lucro apurado corretamente - evidenciando a realidade econômico-financeira reduz os riscos de emprestadores e investidores. Porém, essa percepção está relacionada com a evidência de que os resultados foram apurados independentemente dos grupos de interesses.

Mas, apesar de seu valor, Lopes e Martins (2005, p. 36) o consideram um dos problemas 
tradicionais da Contabilidade, principalmente no que se refere a sua mensuração, pelo fato de ele possuir aspectos subjetivos. Tais aspectos são ajustes oriundos do regime de competência e podem ser denominados accruals.

O accrual contábil faz uso de apropriações, diferimento e atribuição de procedimentos, com o objetivo de relacionar receitas, despesas, ganhos e perdas aos períodos, de forma a refletir um desempenho da entidade, em vez de mera listagem de seus pagamentos e recebimentos em base caixa. Contudo, a norma contábil pode possuir flexibilidade, permitindo ao gestor escolher como e quando alguns eventos econômicos serão reconhecidos. Nesse sentido, os gestores podem optar por práticas consistentes com as normas, mas apresentar informações da maneira que lhes interessar, resultando em um comportamento oportunista. Isso ocorre, pois, como dito e confirmado por Verrecchia (1983), o gestor exerce a discricionariedade, escolhendo o ponto ou o grau da qualidade da informação. Dessa forma, com a flexibilidade nos Generally Accepted Accounting Principles (GAAPs), como salienta Subramanyan (1996, p. 250), os accruals são sujeitos à discricionariedade administrativa, a qual pode aumentar a informação do resultado, permitindo comunicação de informação privada (a princípio reservado aos interesses internos da empresa). Do mesmo modo, os incentivos desalinhados entre agentes e principais podem induzir aqueles a usar a flexibilidade dos GAAPs, para administrar, oportunistamente, o resultado.

Tais accruals podem ser formados por componentes discricionários (discretionary accruals) e não discricionários (nondiscretionary accruals). Segundo Hansen (1999, p. 3) e Martinez (2001, p. 17), aqueles são artificiais, não usuais e teriam como objetivo somente manipular o resultado contábil com a finalidade de iludir os usuários da informação contábil. Os accruals não discricionários são intrínsecos às atividades da empresa e pro- venientes dos princípios contábeis, portanto utilizados para reduzir a assimetria informacional entre a empresa e os usuários das demonstrações contábeis.

Logo, há dois caminhos que podem ser seguidos pela empresa: a) aquele em que o gestor toma a decisão para garantir o bemestar de todas as partes ou b) aquele em que o gestor procura principalmente maximizar sua utilidade, podendo ser em detrimento da riqueza das partes. $\mathrm{O}$ fato é que as escolhas que visam alcançar, primordialmente, o objetivo próprio, podem ser encaradas como fruto de atitudes oportunistas. Em função disso e com base na teoria de agência, verifica-se que as pessoas procuram maximizar a própria utilidade e que, por isso, há motivos para se considerar que um agente nem sempre atuará respeitando o interesse do principal. Nesse contexto, o GR foi visto como uma forma de o gestor manipular os resultados, em busca de benefícios particulares, podendo alterar a percepção dos usuários quanto aos aspectos econômicos e financeiros das empresas, e há incentivos para que eles façam isso. Portanto, uma empresa com histórico de GR oportunista passaria uma imagem insegura - dada a maior possibilidade de risco moral e assimetria de informações aos credores, que, por sua vez, poderiam elevar o retorno exigido ao investirem seus recursos nessa empresa. Por essa razão, espera-se que o GR tenha efeitos no custo de captação de dívida das empresas, o que, se comprovado, significa que o nível de GR da companhia pode impactar em seus custos externos de captação.

\subsection{Escolhas Contábeis e Gerenciamento de Resultados}

A definição de GR ganha diversas expressões entre os pesquisadores nacionais e internacionais. A título de exemplo seguem algumas definições, no Quadro 10.

Percebe-se que as duas primeiras definições são semelhantes, ao considerar o GR com objetivo de enganar ou alcançar objeti- 


\section{Quadro 1 Definições de gerenciamento de resultados}

\begin{tabular}{l|l}
\hline Autores & Definições para "gerenciamento de resultados" \\
\hline Schipper (1989, p. 89) & $\begin{array}{l}\text { "... uma intervenção proposital no processo da elaboração das demonstrações } \\
\text { financeiras externas, com a intenção de obter algum benefício particular..." (Grifo } \\
\text { nosso). }\end{array}$ \\
\hline Healy e Whalen (1999, p. 368) & $\begin{array}{l}\text { "O gerenciamento de resultados contábeis ocorre quando o administrador utiliza } \\
\text { de julgamento nos relatórios financeiros, para enganar alguns agentes sobre o } \\
\text { desempenho econômico da empresa, ou para influenciar os resultados contratuais } \\
\text { que dependem dos números contábeis." (Grifo nosso). }\end{array}$ \\
\hline $\begin{array}{l}\text { Richardson (2000, p. 325) } \\
\text { "Padrões contábeis permitem uma discricionariedade gerencial na aplicação de } \\
\text { métodos contábeis usados para reportar o desempenho das empresas. Quando esta } \\
\text { discricionariedade é usada com a intenção de manipular resultados reportados, ela } \\
\text { p. 506) }\end{array}$ & $\begin{array}{l}\text { chamada de gerenciamento de resultados." (Grifo nosso). } \\
\text { enganar alguns stakeholders ou para influenciar resultados contratuais." (Grifo } \\
\text { Field, Lys e Vincent (2001, } \\
\text { Watts e Zimmerman (1990) }\end{array}$ \\
\hline \hline
\end{tabular}

vos particulares, mas a última definição não implica que o GR seja algo negativo ou oportunista, mas, de qualquer forma, ele modifica a informação contábil, portanto, pode ser considerada uma definição mais abrangente.

Quanto aos tipos de GR, existem algumas maneiras de o gestor ou a empresa gerenciar o resultado contábil a ser divulgado, por exemplo: a) Gerenciamento de accruals (feito por meio de escolhas contábeis dentro dos GAAP); b) Contabilidade fraudulenta (nesse caso o GR ocorre com violação dos princípios contábeis) e c) Gerenciamento de resultados reais (intervenção do gestor por meio de decisões operacionais, como compra de matériaprima, descontos concedidos, venda de ativo fixo para afetar ganhos e perdas etc.).

Além das maneiras de gerenciar resultados, há diversos motivos que influenciam tal prática, sendo os mais citados pela literatura nacional e internacional os seguintes, ver Quadro 20.

Um dos motivos para o GR, segundo Martinez (2001), é o Income Smoothing, que significa um lucro estável com pequenas flutuações, o que denota, segundo o autor, redução no custo de capital de terceiros, pois a apresentação de bons resultados presta-se como inegável benefício para a empresa, que estará tentada a sinalizar estabilidade econômica de modo a permitir o cumprimento dos compromissos financeiros.

Além disso, destacou-se, no Quadro 2, que os administradores são pressionados pelos covenants ou outras restrições dos compromissos assumidos pela empresa. A existência desses mecanismos é uma prova do conflito de agência, pois, sabendo que os administradores têm uma tendência natural em assumir riscos maiores do que o desejado, os credores impõem algumas restrições. Assim, é natural que, quando os covenants estiverem relacionados com os indicadores contábeis, os gestores tendem a "administrar os resultados", pois o incentivo, segundo Watts e Zimmerman (1990, p. 133), Healy e Whalen (1999) e Lopes e Martins (2005, p. 46), de manter os covenants e outras restrições é potencializar a 
Quadro 2 Alguns motivos para o gestor gerenciar resultados

\begin{tabular}{|c|c|}
\hline Autores & Motivos para fazer GR \\
\hline $\begin{array}{l}\text { Verrecchia (1983); Healy e Whalen (1999) e Field, Lys e } \\
\text { Vincent (2001) }\end{array}$ & $\begin{array}{l}\text { Influenciar a percepção do mercado e elevar o preço } \\
\text { das ações. }\end{array}$ \\
\hline Field, Lys e Vincent (2001) e Watts e Zimmerman (1990) & Vinculados ao mercado de capitais e externalidades. \\
\hline $\begin{array}{l}\text { Subramanyan (1996); Sunder (1997); Hendrinksen e Van } \\
\text { Breda (1999) e Martinez (2001) }\end{array}$ & Income Smoothing. \\
\hline Verrecchia (1983) e Field, Lys e Vincent (2001) & Manter imagem e mostrar talento. \\
\hline Sunder (1997) e Martinez (2001) & Preservar o cargo e busca de status. \\
\hline Martinez (2001, p. 1) e Andrade e Rossetti (2006, p. 204) & $\begin{array}{l}\text { Pressão dos acionistas por resultados maiores e de outros } \\
\text { interesses da diretoria executiva. }\end{array}$ \\
\hline Healy e Whalen (1999) e Lopes e Martins (2005) & Sistema de remuneração e procura para manter bônus. \\
\hline $\begin{array}{l}\text { Holthausen e Leftwhich (1983); Watts e Zimmerman } \\
\text { (1990); Healy e Whalen (1999); Field, Lys e Vincent } \\
\text { (2001) e Lopes e Martins (2005) }\end{array}$ & $\begin{array}{l}\text { Motivos contratuais. Manter os covenants e outras restri- } \\
\text { ções ou potencializar a obtenção de empréstimos. }\end{array}$ \\
\hline
\end{tabular}

obtenção de empréstimos. Isso seria o que se pode chamar de "gerenciamento de resultados pós-contrato", ou seja, significa gerenciar resultados para atender às restrições contratuais impostas hoje para facilitar a obtenção de recursos amanhã, e até custos reduzidos.

Além dos motivos expostos, Coelho e Lopes (2007, p. 128) salientam que as escolhas contábeis têm o objetivo de atender às necessidades das empresas a respeito da captação de recursos de terceiros, e que os gestores podem: “...numa lógica oportunística ou no enfoque de maximização do valor da firma, apresentarem as informações contábeis de forma a induzir credores a assumirem postura favorável à empresa." O objetivo desse comportamento é preparar dados para facilitar a aprovação de limites de crédito ou liberação de recursos.

\subsection{Pesquisas sobre Gerenciamento de Resultados}

De acordo com Francis et al. (2002, p. 5), as empresas podem afetar o retorno exigido pelas fontes de recursos, diminuindo a quantidade de informação privada e aumentando a precisão ou a qualidade da informação pública. Além disso, maior qualidade nos resultados reportados, por exemplo, fornece um sinal mais preciso a essas fontes. Easley e O'Hara (2001) corroboram e destacam que um papel importante da informação contábil precisa é reduzir o custo de captação, por diminuir o risco baseado na informação.

Dessa forma, existe uma relação positiva entre a assimetria informacional e o custo de capital das empresas, pela possibilidade de reduzir o risco enfrentado pelas fontes de financiamento, conforme destacam Alencar (2005), Easley e O'Hara (2001) e Francis et al. (2002). Mas, dentre as diversas informações geradas pela contabilidade, Francis et al. (2005) destacam o resultado contábil reportado, afirmando que ele é fonte importante de informação e seus atributos são desejáveis na redução do risco de informação, resultando em vantagens, em nível de informação, para o mercado. Por outro lado, Boubakri e Ghouma (2008) salientam que o gestor usará sua discricionariedade para alterar os resultados reportados, por duas razões principais: a) encontrar dívida adequada para financiar seus projetos; b) e/ou respeitar as restrições do contrato de dívida. 
A respeito da utilidade da informação contábil aos fornecedores de recursos, Coelho (2007, p. 16) destaca: a) é uma fonte de dados necessária para a avaliação da empresa a ponto de orientar as decisões de alocação de capitais e b) é a base para o monitoramento da capacidade de reaver os recursos investidos. Nesse sentido, algumas linhas de estudo vêm explorando a relação entre GR e o custo de captação, principalmente no meio acadêmico internacional, sendo essa relação pouco explorada no Brasil. A título de exemplo têmse o exposto no Quadro 30.
Percebe-se que uma das relações estudadas é entre GR e custo da dívida, com destaque aos trabalhos Francis et al. (2002 e 2005). Nesses trabalhos, os autores verificaram que firmas com menos qualidade nos resultados têm maior custo de capital, evidenciado pelo baixo índice de ratings, e que as firmas com maior qualidade dos resultados apresentam desconto de 80-160 pontos bases em seu custo da dívida. Surgiu, assim, o interesse em verificar qual seria a relação entre GR e custo da dívida no Brasil.

Quadro 3 Abordagens e métodos para identificação de GR nas pesquisas internacionais

\begin{tabular}{|c|c|c|}
\hline Trabalhos & Relações & Métodos de identificação de GR \\
\hline Sengupta (1998) & Ki versus GR & Relatório de qualidade de informação. \\
\hline Francis et al. (2002) & Ki e Ke versus GR & $\begin{array}{l}\text { Modelos: Dechow, Sloan e Sweeney (1995), } \\
\text { Teoh et al. (1998) e Dechow e Dichev (2002). }\end{array}$ \\
\hline Francis et al. (2004) & Ke versus GR & Modelo de Dechow e Dichev (2002). \\
\hline Francis et al. (2005) & Ki e Ke versus GR & $\begin{array}{l}\text { Modelos: Dechow, Sloan e Sweeney (1995) e } \\
\text { Dechow e Dichev (2002). }\end{array}$ \\
\hline Aboody, Hughes e Liu (2005) & Ke versus GR & $\begin{array}{l}\text { Modelos: Dechow, Sloan e Sweeney (1995) e } \\
\text { Dechow e Dichev (2002). }\end{array}$ \\
\hline Leuz e Verrecchia (2005) & Ke versus GR & Modelo Econômico. \\
\hline $\begin{array}{l}\text { Francis, Khurana e Pereira } \\
\text { (2005) }\end{array}$ & Ke versus GR & $\begin{array}{l}\text { Índice de evidenciação baseado na análise de } \\
\text { demonstrações contábeis. }\end{array}$ \\
\hline $\begin{array}{l}\text { HassabEnably, Mosebach e } \\
\text { Whisenant (2005) }\end{array}$ & Default técnico versus GR & $\begin{array}{l}\text { Mudanças nas escolhas contábeis e Modelo de } \\
\text { Dechow, Sloan e Sweeney (1995). }\end{array}$ \\
\hline Coelho e Lopes (2007) & GR versus Alavancagem & Modelo de Dechow, Sloan e Sweeney (1995). \\
\hline $\begin{array}{l}\text { Bharath, Sunder e Sunder } \\
\text { (2008) }\end{array}$ & $\begin{array}{l}\text { Custo dos juros, maturidade e } \\
\text { bens em garantia versus GR }\end{array}$ & $\begin{array}{l}\text { Modelos: Jones (1991); Dechow, Sloan e } \\
\text { Sweeney (1995); Teoh et al. (1998) e Dechow } \\
\text { Dichev (2002). }\end{array}$ \\
\hline Paulo et al. (2008) & GR versus rating & Modelos: Jones e KS. \\
\hline
\end{tabular}

Em que: Ki refere-se ao custo da dívida; Ke refere-se ao custo de capital próprio e GR é o gerenciamento de resultados observado por métodos descritos na última coluna.

\section{METODOLOGIA}

\subsection{Delimitação}

A pesquisa foi realizada com as empresas brasileiras abertas, cujas demonstrações contábeis e outras informações foram obtidas do banco de dados Economática e da CVM. Quanto ao período de análise, trabalhou-se 
com o intervalo de tempo de 1997 a 2007. A limitação dessa amostra, bem como do período considerado, foi motivada pela facilidade em obter informações e pela necessidade de empresas com informações contábeis exigidas no modelo para cálculo dos accruals discricionários, os quais foram obtidos por meio do modelo desenvolvido por Kang e Sivaramakrishnan (1995) - KS. Na amostra final, contam-se 229 empresas ou 1.853 observações no período de análise.

Cabe considerar que a presente pesquisa pautou-se na análise das variáveis "Gerenciamento de Resultados" e "Custo da Dívida” por meio de equações simultâneas e outros testes não paramétricos. Contudo, outras relações poderiam ser exploradas, bem como outros caminhos estatísticos são possíveis.

\subsection{Hipóteses}

Como verificado, a literatura aponta que motivos contratuais e a necessidade de adquirir condições de empréstimos favoráveis, como baixo custo, são motivações para as empresas fazerem certas escolhas contábeis ou para gerenciar seus resultados. Assim, um dos motivos do GR seriam os aspectos contratuais com credores, entre eles o custo da dívida. Empresas com maior custo de endividamento tenderiam a gerenciar o resultado, iludindo os credores quanto à real situação do desempenho econômico e financeiro da empresa, de modo que maiores custos de dívida conduziriam a níveis maiores de GR. Consequentemente, o GR seria capaz de interferir na decisão dos credores, apontando uma empresa com condições econômicas e financeiras suficientes para que aqueles estabeleçam retorno com menor prêmio exigido, ou seja, custos da dívida mais favoráveis para as empresas. Nesse caso, níveis maiores de GR conduziriam a custo da dívida menor para as companhias. Desse modo, haveria uma inter-relação entre o custo da dívida e o GR feito pelas empresas, em que o custo atual ou passado motiva o GR corrente (maior custo, maior gerenciamento) para impacto nas condições de custo futuro ou, ainda, no custo corrente (maior gerenciamento, menor custo).

Diante disso, surge a seguinte hipótese da pesquisa: Hipótese 1: Há uma inter-relação entre o GR e o custo da dívida das empresas brasileiras abertas.

Desse modo, o modelo conceitual dessa hipótese é um sistema com as funções:

$$
\left\{\begin{array}{l}
G R_{i t}=f\left(K i_{i t} \text { e variáveis pré-determinadas }\right) \\
K i_{i t}=f\left(G R_{i t} \text { e variáveis pré-determinadas }\right)
\end{array}\right.
$$

Contudo, apesar dos pressupostos considerados na hipótese 1 , há fundamentação teórica de que a relação entre GR e custo da dívida seja unidirecional, com o GR influenciando o custo da dívida das empresas, como abordam Francis et al. (2002 e 2005) e Boubakri e Ghouma (2008). Acontece que, devido às relações de agência, assimetria de informações e o uso das demonstrações contábeis para analisar a situação da empresa, há argumentos favoráveis de que o GR tenha impacto no custo da dívida das empresas, pois se o GR for percebido como uma possibilidade de assimetria informacional, os credores, sentindo-se em um ambiente menos seguro, exigirão um prêmio maior pelo risco da falta de informação, o que elevaria o custo de captação por esses recursos para as empresas. Dessa forma, espera-se uma relação positiva entre GR e o custo de dívida.

Assim, com base no pressuposto de que o GR significa assimetria informacional e consequente aumento no custo da dívida, pode haver indícios de que relação unidirecional seja de o GR implicando no custo da dívida. Portanto, a segunda hipótese da pesquisa é: Hipótese 2: A relação entre o GR e o custo da dívida das empresas brasileiras abertas é unidirecional e positiva, sendo o custo da dívida dependente do GR.

Diferentemente da intenção em gerenciar o resultado da hipótese 1 , no caso da segun- 
da hipótese o GR não teria como propósito influenciar o custo da dívida, mas, sim, objetivar outras motivações, tendo um impacto indireto nos credores, que percebem o GR como possível assimetria de informações.

A possibilidade de relação negativa entre as variáveis não foi considerada, pois não possui pesquisas anteriores que sustentem a possibilidade de que, dada uma relação unidirecional, o GR influencie o custo da dívida a ponto de que a relação seja negativa, sem motivação prévia ou que os credores não percebam o GR ou percebam, mas o considerem como melhoria na qualidade da informação divulgada. Da mesma forma, se não houver inter-relação, também, não há suporte teórico para a relação unidirecional com o custo da dívida causando o GR, de modo positivo ou negativo, sem esperar como consequência modificações instantâneas ou posteriores no custo da dívida.

\subsection{Variáveis}

As variáveis explicadas e explicativas selecionadas tiveram base nas pesquisas anteriores, sendo listadas na Tabela $1 \boldsymbol{\nabla}$, juntamente com a relação esperada com GR e Ki e a forma de cálculo.

Tabela 1 Variáveis da pesquisa

\begin{tabular}{|c|c|c|c|c|}
\hline Variáveis & Sigla & GR & Ki & Forma de Cálculo \\
\hline $\begin{array}{l}\text { Gerenciamento } \\
\text { de Resultados }\end{array}$ & GR & & $+/-$ & $\begin{array}{l}\text { Resíduo do modelo: } \\
A C T_{i t}=\emptyset_{0}+\emptyset_{1} \times\left[\frac{A R_{i t-1}}{R E V_{i t-1}} \times R E V_{i t}\right]+\emptyset_{2} \times\left[\frac{A P B_{i t-1}}{E X P_{i t-1}} \times E X P_{i t}\right]+\emptyset_{3} \times\left[\frac{D E P_{i t-1}}{G P P E_{i t-1}} \times G P P E_{i t}\right]+v_{i t}\end{array}$ \\
\hline Custo da Dívida & $\mathrm{Ki}$ & $+/-$ & & $K i_{i t}=$ Des.Financ ${ }_{i t} / P O_{i t-1}$ \\
\hline $\begin{array}{l}\text { Ciclo Opera- } \\
\text { cional }\end{array}$ & $\mathrm{CO}$ & + & & $C O_{i t-1}=\left[360 /\left(\right.\right.$ Vendas $\left.\left._{i t-1} / \Delta C R_{i t-1}\right)\right]+\left[360 /\left(C M V_{i t-1} / \Delta\right.\right.$ Estoque $\left._{i t-1}\right]$ \\
\hline $\begin{array}{l}\text { Resultados } \\
\text { Negativos }\end{array}$ & LL & + & & Variável Categórica: 1 para resultado negativo e 0 (zero) caso contrário \\
\hline $\begin{array}{l}\text { Income } \\
\text { Smoothing }\end{array}$ & Smoo & + & & $\begin{array}{l}\text { Variável Categórica: } 1 \text { se a variação do resultado estiver entre }-1 \% \text { a } 1 \%, 0 \\
\text { (zero) caso contrário }\end{array}$ \\
\hline Desempenho & Desemp & $+/-$ & & Desemp $_{i t-1}=E B I_{i t-1} /$ Invest $_{i t-1}$ \\
\hline ADR & ADR & + & & Variável Categórica: 1 se a empresa emite ADR, 0 (zero) caso contrário \\
\hline Crescimento & Cresc & + & & $\operatorname{CresC}_{i t-1}=\left(A T_{i t-1}-A T_{i t}\right) / A T_{i t-1}$ \\
\hline Tangibilidade & Tang & & - & $\operatorname{Tang}_{i t-1}=\left(\operatorname{Im} o b L i q_{i t-1}-R R_{i t-1}\right) /\left(A T_{i t-1}-R R_{i t-1}\right)$ \\
\hline $\begin{array}{l}\text { Cobertura } \\
\text { das Dívidas }\end{array}$ & FCx & & - & $F_{C X_{i t-1}}=E B I T D A_{i t-1} / P O_{i t-1}$ \\
\hline Tamanho & Tam & - & - & $\operatorname{Tam}_{i t}=\log A T_{i t}$ \\
\hline Idade & Idade & + & - & Dados disponíveis na CVM - Data t da observação \\
\hline Leverage & Lev & + & + & $L e v_{i t-1}=\operatorname{Div} L P_{i t-1} / A T_{i t-1}$ \\
\hline Volatilidade & Volat & + & + & Desvio-padrão do fluxo de caixa para a realização das dívidas \\
\hline
\end{tabular}

$A C T_{i t}=$ accruals totais; $A R_{i t-1}=$ saldo de contas a receber de curto prazo; $R E V_{i t-1}=$ receita líquida de vendas; $A P B_{i t-1}=$ saldo da conta de estoque mais saldo da conta de despesas antecipadas, mais saldo das contas a pagar de curto prazo; $E X P_{i t-1}=$ despesas operacionais; $D E P_{i t-1}=$ despesa de depreciação e amortização; $G P P E_{i t-1}=$ saldo de ativo imobilizado e diferido; Des. Financ $_{i t}=$

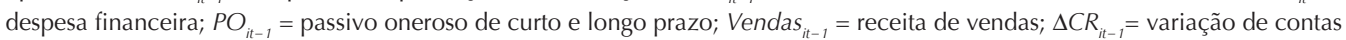
a receber; $C M V_{i t-1}=$ custo da mercadoria vendida; $\Delta$ sstoque $_{i t-1}=$ variação de estoques; $E B I_{i t-1}=$ lucro antes dos juros; Invest $t_{i t-1}=$ Investimento; $E B I T D A_{i t-1}=$ lucro antes de juros, impostos e despesa de depreciação e amortização; $\log A T_{i t}=\operatorname{logaritmo}$ do ativo total; ImobLiq $_{i t-1}=$ imobilizado líquido; $R R_{i t-1}=$ reserva de reavaliação; $A T_{i t-1}=$ ativo total; $D i ́ v L P_{i t-1}=$ dívida de longo prazo 


\section{Como justificativa das variáveis selecionadas, podem-se resumir os seguintes aspectos, ver Quadro 40.}

Quadro 4 Variáveis e Justificativa de uso

\begin{tabular}{|c|c|}
\hline Variável & Justificativa \\
\hline GR & $\begin{array}{l}\text { Como variável do GR, optou-se pelos accruals discricionários provenientes do modelo de Kang e Siva- } \\
\text { ramakrishnan (1995, p. 353-355). McNichols (2003, p. 318) salienta que, nos anos de } 1993 \text { a 1999, o } \\
\text { maior número de artigos a respeito de GR foi publicado no Journal of Accounting and Economics e que, } \\
\text { de } 56 \text { artigos, } 26 \text { procuram separar os accruals com uso de modelos. Portanto, dizem que é um método } \\
\text { amplamente aceito, embora outros autores discordem. Nesse sentido, Thomas e Zhang (2000) compa- } \\
\text { raram a habilidade preditiva de seis modelos de accruals e chegaram à conclusão de que o modelo KS } \\
\text { desempenhou-se bem em relação aos outros. }\end{array}$ \\
\hline Ki & $\begin{array}{l}\text { O cálculo do custo da dívida considerou, apenas, as despesas financeiras constantes da Demonstração } \\
\text { de Resultados (DRE), seguindo a metodologia utilizada por Sengupta (1998, p. 462); Francis et al. (2002); } \\
\text { Francis, Khurana e Pereira (2005); Francis et al. (2005) e Lima (2007, p. 30). Sobre a relação entre GR e } \\
\text { custo da dívida, Francis et al. (2002; 2005) encontraram que quanto maior o GR, maior o custo para o } \\
\text { endividamento externo das companhias. }\end{array}$ \\
\hline $\mathrm{CO}$ & $\begin{array}{l}\text { O uso do ciclo operacional por Gu, Lee e Rosett (2005) ocorre, pois, quando o ciclo operacional da em- } \\
\text { presa é longo, ela requer mudanças nos níveis de capital circulante. Assim, accruals podem ser utilizados } \\
\text { para reduzir a época e os problemas de compatibilização do fluxo de caixa. }\end{array}$ \\
\hline LL & $\begin{array}{l}\text { A necessidade de separar resultados divulgados negativos e positivos é que aqueles podem conter mais } \\
\text { componentes transitórios do que os lucros, podendo ser devido ao conservadorismo contábil, sendo que } \\
\text { parte desses componentes se deve aos accruals. Assim, a relação esperada está baseada na ideia do "Big } \\
\text { Bath Accounting", em que o resultado é gerenciado no período corrente, de modo a aumentar o lucro } \\
\text { futuro, conforme abordou Martinez (2001, p. 43). }\end{array}$ \\
\hline Smoo & $\begin{array}{l}\text { Subramaryan (1996, p. 251) salienta que o gestor pode "melhorar" o valor do resultado, suavizando-o. } \\
\text { A esse respeito, Martinez (2001, p. 43) verifica que as empresas brasileiras fazem escolhas para reduzir a } \\
\text { variabilidade do resultado a ser reportado, sendo que esse é um motivo que leva as empresas a gerencia- } \\
\text { rem seus resultados. }\end{array}$ \\
\hline Desemp & $\begin{array}{l}\text { Guay, Kothari e Watts (1996, p. 83) especificam três hipóteses a respeito dos accruals discricionários. } \\
\text { Em uma delas, afirmam que os accruals ajudam os gestores a produzir uma medida mais confiável do } \\
\text { desempenho da empresa. Nesse caso, o accrual reflete a tentativa da administração em aumentar a } \\
\text { habilidade dos resultados para que esse reflita o desempenho em um modo seguro e conveniente, e que } \\
\text { poderia esperar uma redução no risco da informação. Guay, Kothari e Watts (1996, p. 104) concluíram } \\
\text { que o efeito líquido dos accruals discricionários é aumentar o resultado como um indicador de desempe- } \\
\text { nho. Portanto, diante dessa possibilidade, optou-se por uma variável de controle capaz de "eliminar" a } \\
\text { parte dos accruals que poderiam ser provenientes do desempenho da empresa. }\end{array}$ \\
\hline ADR & $\begin{array}{l}\text { Empresas que emitem ADR estão mais sujeitas a exames detalhados por investidores estrangeiros e re- } \\
\text { guladores, segundo Francis, Khurana e Pereira (2005, p. 1137). Portanto, espera-se que as empresas que } \\
\text { negociam ADRs tenham menor gerenciamento de resultados contábeis. }\end{array}$ \\
\hline Cresc & $\begin{array}{l}\text { De acordo com Gu, Lee e Rosett (2005), o crescimento da empresa, por meio de ativos, pode vir de duas } \\
\text { formas: mediante financiamento externo ou por resultados operacionais internos. O nível de leverage } \\
\text { pode afetar o GR, mas, conforme verificado por Dechow Sloan e Sweeney (1995), o accrual é correla- } \\
\text { cionado com o desempenho interno da empresa. Assim, espera-se que a empresa em crescimento possa } \\
\text { ter maior variabilidade nos accruals. Desse modo, o crescimento como variável de controle para GR foi } \\
\text { usado por Gu, Lee e Rosett (2005), os quais esperavam uma relação positiva. }\end{array}$ \\
\hline
\end{tabular}


continuação

De acordo com Valle (2007, p. 43), a tangibilidade dos ativos é usada, pois é a relação de ativos que pode ser dadas em garantia nos contratos de dívida. O que ocorre, teoricamente, é que dívidas feitas com ativos dados em garantia ou posting collateral, reduzem a flexibilidade do tomador de emitir dívidas

Tang adicionais sobre esse ativo, por exemplo. Isso significa maior segurança, o que pode reduzir a taxa de juros exigida pelos credores; então, esses ativos podem diminuir o custo de agência da dívida para os credores. Consequentemente, espera-se uma relação positiva entre a quantidade de tangíveis e a disposição dos credores em financiar; logo, maior deve ser a alavancagem.

De modo semelhante, foi estabelecida uma variável representativa da capacidade de cobertura das dívidas. Então, relacionou-se o fluxo de caixa para fins de cumprimento das dívidas com as dívidas totais da empresa. Essa relação indica quanto do fluxo de caixa da empresa é suficiente para cobrir suas dívidas, ou seja, relaciona a possível capacidade da empresa em evitar dificuldades financeiras.

Segundo Gu, Lee e Rosett (2005, p. 315), o tamanho da empresa é uma das mais importantes características, pois as empresas maiores desfrutam de mais benefício de escala e economia de escopo do que as empresas menores; são mais maduras, operam em um estado mais sólido e tendem a ser mais diversificadas. Essas características permitem dizer que tais empresas têm menor variabilidade operacional, portanto, menor variabilidade dos accruals. Além disso, elas têm menos incentivos ao GR devido aos custos políticos. Tais características foram usadas pelos autores para explicar a relação negativa entre tamanho e GR, ou seja, empresas maiores possuem menos discrição nos accruals. Por outro lado, Richardson (2000, p. 332) salienta que o tamanho da empresa pode ter relação positiva com o GR, pois Tam empresas maiores têm mais incentivo para reduzir os custos políticos, o que, por sua vez, incentivaria o GR. Apesar disso, o autor encontra um coeficiente significativamente negativo, como o resultado de Gu, Lee e Rosett (2005, p. 315). O tamanho da empresa, também, parece ter uma relação com o custo da dívida das companhias. Valle (2007, p. 40), por exemplo, destaca que as empresas maiores têm acesso mais fácil ao mercado de capitais; mais ativos que podem ser dados em garantia, no caso de contratos de dívida; podem ser mais diversificadas, o que as tornam menos propensas à falência. Essa característica, a princípio, facilita a obtenção de recursos externos a um custo menor, o que, por sua vez, pode implicar maior proporção de capital de terceiros. Da mesma forma, Sengupta (1998) afirma que devido à economia de escala, o custo da dívida pode ser inversamente proporcional ao tamanho.

O uso dessa variável parte da idéia de que, normalmente, se conhece mais a respeito de empresas mais velhas, o que é possível devido aos seus históricos. Isso quer dizer que maiores desvios no histórico da companhia são mais fáceis de detectar; além disso, empresas maduras tendem a ter um estado mais sólido de desempenho financeiro e operacional. De tal maneira, pode-se esperar que empresas velhas tenham menos variabilidade nos accruals, segundo Gu, Lee e Rosett (2005, p. 319).

Por outro lado, acredita-se que tais empresas podem querer manter resultado e desempenho que vinha sendo reportado. Assim, podem ter motivos para gerenciar o resultado ao longo do tempo, conseguindo manter a imagem que vinha tendo. Logo a relação entre GR e a idade das empresas seria positiva. Em relação ao custo da dívida, empresas mais velhas apresentam um histórico de longo prazo para a análise dos credores, os quais conseguem definir melhor o perfil da empresa e acompanhar sua liquidez, assim, espera-se que empresas mais velhas consigam custos de dívida menores. Nesse sentido, Mansi, Maxwell e Miller (2007, p. 13) destacam que um histórico longo sobre a empresa deve reduzir a assimetria de informações entre os insiders e analistas, agências de ratings e investidores, permitindo previsões mais acuradas sobre os resultados futuros da empresa.

Empresas com mais dívidas podem ser vistas como mais arriscadas. Portanto, espera-se uma relação positiva com o custo da dívida. No entanto, Gu, Lee e Rosett (2005) usaram a variável leverage como variável de controle para GR e encontraram relação positiva entre elas, sugerindo, segundo os autores, que o uso do resultado no contrato de dívidas induz o gestor a exercer mais discrição contábil. Além disso, Watts e Zimmerman (1990) afirmaram que, quanto mais endividada a empresa, mais provável que o gestor selecione procedimentos contábeis para aumentar o lucro. 
A respeito da volatilidade, também conhecida como medida de risco, Valle (2007, p. 67) argumenta que as empresas menos arriscadas têm menor custo de falência, portanto, podem ter prazos de dívidas mais alongados, o que pode impactar na opção por fontes de financiamento de recursos. Nesse trabalho, optou-se por usar o desvio-padrão do fluxo de caixa, como empregado por Francis et al. (2002 e 2005), os quais consideram os dados das empresas até cinco anos da data desejada. Cabe ressaltar que essa metodologia possui como limitação o fato de que nem todas as empresas possuem dados de cinco anos antes de 1997, sendo que a média dos períodos substituiu os dados desses anos. Gu, Lee e Rosett (2005) utilizaram como variável de controle para suas proxies de GR a variabilidade do fluxo de caixa e salientam que quando as empresas operam em ambientes voláteis, com grandes mudanças em capital de giro, investimentos e financiamentos, os accruals tendem a variar mais, sugerindo que maior volatilidade operacional leva a uso mais pesado dos accruals para mitigar os problemas de "timing" e compatibilização do fluxo de caixa. Além disso, a questão da variabilidade esbarra na idéia de gerenciamento

Volat oportunista dos accruals para manter os resultados suavizados - income smoothing. Sobre esse aspecto, Hendrinksen e Van Breda (1999) salientam que a estabilização do lucro divulgado é uma preocupação com os credores, pois empresas endividadas devem realizar tudo o que for possível para se apresentarem capazes de cumprir seus compromissos financeiros. Desse modo, a divulgação de bons resultados contábeis presta-se como inegável benefício para a empresa que, sinalizando estabilidade econômica, mostra-se apta para cumprir seus compromissos financeiros. Assim, quanto mais endividada a empresa, maior será sua propensão para gerenciar os resultados para mostrar situação estável.

Dechow e Dichev (2002, p. 47), também, controlaram o gerenciamento de resultados pela volatilidade do fluxo de caixa e esperam que, se essa volatilidade for baixa, mais estável serão os accruals. Segundo as autoras, alto desvio-padrão dos fluxos é uma medida de elevada incerteza no ambiente operacional que pode estar acompanhada de incertezas nos accruals. Francis et al. (2004, p. 974), também, usaram a variabilidade do fluxo de caixa para dar ideia de suavização, apoiando-se na ideia de que a suavização é um atributo desejável do lucro e derivam do ponto de vista de que os gestores usam informações privadas para suavizar as flutuações transitórias a fim de alcançar resultado com representatividade e mais útil.

\subsection{Métodos}

Quanto aos métodos, inicialmente, foi aplicado o teste de normalidade (teste Kolmogorov-Smirnov) para todas as variáveis, cujo resultado rejeitou a hipótese de normalidade para todas elas. Em seguida, foi feita uma análise de inferência de média entre o primeiro e o quarto quartil das variáveis de GR, Ki e as de controle. Para isso, utilizou-se o teste não paramétrico U de Mann-Whitney.

A próxima análise foi verificar a possibilidade de inter-relação entre GR e o custo da dívida, que foi feita por meio de equações simultâneas, cujas variáveis estão definidas no Quadro 50.

Desse modo, o sistema de equações estruturais desse estudo é definido pelas seguintes equações:

$$
\begin{aligned}
& G_{i t}=\alpha_{0}+\alpha_{1} \operatorname{Ki}_{i t}+\alpha_{2} \operatorname{Tam}_{i t}+\alpha_{3} \mathrm{CO}_{i t-1}+ \\
& \alpha_{4} \text { Desemp }_{i t-1}+\alpha_{5} \text { Idade }_{i t}+\alpha_{6} \text { Cresc }_{i t}+
\end{aligned}
$$

$$
\begin{aligned}
& \alpha_{7} \text { Lev }_{i t-1}+\alpha_{8} \text { Volat }_{i t-1}+\alpha_{9} \text { LL }_{i t}+ \\
& \alpha_{10} \text { ADR }_{i t}+\alpha_{11} \text { Smoo }_{i t}+\varepsilon_{i t} \\
& \text { Ki }_{i t}=\beta_{0}+\beta_{1} \text { GR }_{i t}+\beta_{2} \text { Tam }_{i t}+\beta_{3} \text { Idade }_{i t}+ \\
& \beta_{4} \text { Tang }_{i t-1}+\beta_{5} \text { Fcx }_{i t-1}+\beta_{6} \text { Volat }_{i t-1}+ \\
& \beta_{7} \text { Lev }_{i t-1}+\mu_{i t}
\end{aligned}
$$

Ainda nesse segundo tipo de análise, quanto à condição de identificação, optouse pelo uso direto da identificação por rank, em que, pelo menos, um determinante construído seja diferente de zero. Em seguida, foi feito o teste de especificação de Hausman seguindo os passos: a) encontrar a forma reduzida; b) regredir cada variável endógena a todas as variáveis predeterminadas, obtendo os valores previstos de $\mathrm{GR}$ e $\mathrm{Ki}$, bem como de seus respectivos resíduos; c) substituir as equações anteriores nas estruturais (1 e 2) e d) efetuar teste $t$ sobre o coeficiente dos resíduos adicionados na equação estrutural, cuja 
Quadro 5 Variáveis endógenas e predeterminadas

Variáveis endógenas a serem testadas:

Custo da Dívida (Ki)

Gerenciamento de Resultados (GR)

\begin{tabular}{c|c}
\hline \multicolumn{2}{c}{ Variáveis predeterminadas: } \\
\hline Tamanho (Tam) & Volatilidade (Volat) \\
\hline Ciclo Operacional (CO) & Tangibilidade (Tang) \\
\hline Desempenho (Desemp) & Fluxo de caixa (Fcx) \\
\hline Crescimento (Cresc) & $\begin{array}{c}\text { Categórica sobre } \\
\text { prejuízo (LL) }\end{array}$ \\
\hline Idade (Idade) & Categórica sobre ADR (ADR) \\
\hline Leverage (Lev) & Categórica sobre variação do lucro (Smoo) \\
\hline
\end{tabular}

hipótese nula é de que não há simultaneidade. Então, se o coeficiente for estatisticamente significante até $5 \%$, as variáveis (GR e Ki) são determinadas simultaneamente, cabendo o uso de MQ2E - Mínimo Quadrado de Dois Estágios - ou MQ3E - Mínimo Quadrado de Três Estágios. Mas se o coeficiente do resíduo não for significativo até 5\%, então, não se pode afirmar a respeito da simultaneidade entre as variáveis, ou seja, não há indício de um interrelacionamento. Logo os estimadores de MQO
- Mínimo Quadrado Ordinário - e MQG Mínimo Quadrado Generalizado - podem ser utilizados.

Por fim, foi utilizada metodologia de disposição e estudos dos dados em painel que, de acordo com Pindynck e Rubinfeld (2004, p. 288), combina séries temporais e cross section em um sistema de pooling. Cabe ressaltar que os testes foram realizados por meio dos seguintes softwares estatísticos: SPPS 12 e STATA ${ }^{\circ}$ 9.2.

\section{APRESENTAÇÃO E ANÁLISE DOS RESULTADOS}

\subsection{Análise descritiva}

Para calcular a proxy de gerenciamento de resultados, foi feita a regressão, com dados dispostos em painel, do modelo KS, cujos resíduos foram utilizados como variável representativa de GR. Para isso, inicialmente, foi feita a regressão com efeitos fixos e efeitos aleatórios para a seguinte aplicação do teste de Hausman. De acordo com o resultado desse teste, o modelo a ser analisado é o de efeitos fixos. Em seguida, foram feitos testes de heterocedasticidade, correlação serial e multicolinearidade. Tais testes indicaram presença de heterocedasticidade e correlação serial, mas rejeitaram a hipótese de multicolinearidade.
Assim sendo, o passo seguinte foi corrigir o modelo de efeitos fixos para heterocedasticidade e correlação serial, cujo resultado está apresentado na Tabela 20.

Por meio da Tabela 2, percebe-se que o poder de explicação do modelo não é alto, mas o resultado assemelha-se aos encontrados pelas demais pesquisas nacionais que utilizaram o modelo KS. Na Tabela 30 , têm-se tais resultados das pesquisas anteriores, para comparação, dos valores do R2 ajustado.

Desse modo, apesar de o $\mathrm{R}^{2}$ encontrado, nessa pesquisa, ser baixo, ele não difere dos resultados das pesquisas existentes que utilizaram o modelo KS.

Cabe ressaltar que, em função da quanti- 
Tabela 2 Regressão do modelo KS

\begin{tabular}{l|c|c}
\multicolumn{2}{c}{ Modelo KS } \\
\hline \multirow{2}{*}{$\begin{array}{l}\text { Variáveis } \\
\text { explicativas }\end{array}$} & \multicolumn{2}{|c}{ Efeitos Fixos } \\
\cline { 2 - 3 } & Coeficiente & $\mathbf{Z}$ \\
\hline$\delta_{1}$ REV $_{\text {it }}$ & $-0,0067$ & $-0,09$ \\
\hline$\delta_{2}$ EXP $_{i}$ & $-0,1882$ & $-2,29^{* *}$ \\
\hline$\delta_{3} \mathrm{GPPE}_{\mathrm{it}}$ & $-0,5785$ & $-2,91^{* * *}$ \\
\hline Cons $^{*}$ & $-0,0192$ & $-2,13^{* *}$ \\
\hline $\mathrm{R}^{2}$ & \multicolumn{2}{|c}{0,1079} \\
\hline Estatística $F$ & $65,34^{* * *}$ \\
\hline
\end{tabular}

Tabela $3 \quad R^{2}$ ajustado das pesquisas nacionais que utilizaram o modelo KS

\begin{tabular}{|c|c|}
\hline Trabalhos & $\begin{array}{l}\mathrm{R}^{2} \text { ajustado } \\
\mathrm{KS}\end{array}$ \\
\hline Martinez (2001, p. 103) & 0,54 \\
\hline Paulo e Martins (2007, p. 12) & 0,060 \\
\hline Paulo e Leme (2007, p. 10) & 0,034 \\
\hline Formigoni, Paulo e Pereira (2007, p. 13) & 0,048 \\
\hline $\begin{array}{l}\text { Formigoni, Antunes e Paulo } \\
(2007, \text { p. 10) }\end{array}$ & 0,087 \\
\hline Martinez e Faria (2007) & 0,128 \\
\hline Paulo (2007, p. 183) & 0,057 \\
\hline Martinez (2008) & 0,088 \\
\hline Paulo et al. (2008) & 0,055 \\
\hline
\end{tabular}

dade de testes, optou-se por não apresentar o resultado do teste de normalidade e da correlação de Spearman. Contudo, de modo geral, o teste de Kolmogorov-Smirnov rejeitou a hipótese de normalidade e o teste de correlação indicou relação positiva entre GR e Ki.

Quanto ao teste de média U de MannWhitney, os resultados foram os expostos na Tabela 40 .

Os resultados apontam que as empresa com menor GR têm custos médios de 44,8\%, em $t$, enquanto as empresas com maior GR têm, em média, 113,5\% de custo. Isso repre-
Tabela 4 Teste U de Mann-Whitney entre GR e Ki

\begin{tabular}{l|c|c|c|c|c} 
& Q1 & Q2 & Q3 & Q4 & Q4-Q1 \\
\hline $\mathbf{G R}$ & 0,011 & 0,034 & 0,066 & 0,203 & $\mathrm{Z}$ \\
\hline $\mathbf{K i}$ & 0,448 & 0,564 & 0,839 & 1,135 & $-7,437^{* * *}$ \\
\hline $\mathbf{K i}_{\mathbf{t}-1}$ & 0,606 & 0,640 & 0,695 & 1,345 & $-3,803^{* * *}$ \\
\hline & & & & & \\
\hline $\mathbf{K i}$ & 0,119 & 0,249 & 0,386 & 1,958 & \\
\hline $\mathbf{G R}$ & 0,065 & 0,067 & 0,088 & 0,116 & $-7,221^{* * *}$ \\
\hline $\mathbf{G R} \mathbf{t}_{-1}$ & 0,077 & 0,069 & 0,081 & 0,109 & $-5.056^{* * *}$ \\
\hline $\mathbf{K i} \mathbf{t}_{-1}$ & 0,112 & 0,251 & 0,392 & 2,267 & \\
\hline $\mathbf{G R}$ & 0,072 & 0,077 & 0,090 & 0,101 & $-4,248^{* * *}$ \\
\hline
\end{tabular}

*** Significante a $1 \%$

GR: gerenciamento de resultados; Ki: custo da dívida; $Q 1: 0$ a $25 \% ; Q 2: 25,1 \%$ a $50 \% ; Q 3: 50,1 \%$ a $75 \%$; $Q 4: 75,1 \%$ a 100\%; Q4-Q1: diferença das médias entre o $4^{\circ}$ quartil e o $1^{\circ}$ quartil; Z: estatística Z do teste

senta um custo maior, no $4^{\circ}$ quartil, de mais de $68,7 \%$, ou seja, maior GR é acompanhado por maior custo da dívida. Essa diferença foi significativa, estatisticamente, a $1 \%$. Resultado semelhante foi verificado na análise do custo médio em t-1. Esse resultado pode sugerir que as diferenças são economicamente significantes, ao ponto de indicaram um custo baixo para empresas com baixo GR ou vice-versa.

Fazendo a análise inversa, ou seja, ordenando o custo da dívida em $\mathrm{t}$ e em $\mathrm{t}-1$ para verificar o comportamento do GR, os resultados apontaram que maiores custos da dívida são acompanhados de maior GR e as diferenças entre o primeiro e o último quartil das médias de GR são estatisticamente significantes a $1 \%$.

\subsection{Teste de simultaneidade}

Para verificar a inter-relação entre o gerenciamento de resultados e o custo da dívida, como levantado na hipótese 1 do estudo, uma das maneiras é considerar uma 
relação simultânea entre as variáveis, para a seguinte aplicação do teste de especificação de Hausman, ou teste de simultaneidade.

Assim, como descrito no capítulo anterior, para se conferir a adequação do modelo estrutural nas condições necessárias para o uso de equações simultâneas, foi feita a verificação da identificação dos modelos com a condição de rank.

$\mathrm{Na}$ Tabela $5 \boldsymbol{\nabla}$, tem-se o teste de identificação do modelo de GR, conforme passos anteriormente descritos.

De acordo com Gujarati (2000), K é o número de variáveis excluídas, ou seja, são as variáveis que se têm em um modelo, mas não em outro, e N é o número de equações do sistema. Assim, se:

$K=(N-1)$ : há uma equação exatamente identificada;

$K>(N-1)$ : a equação é sobreidentificada; $e$ $K<(N-1)$ : a equação está subidentificada.

Caso essa última condição seja observada, não se pode aplicar o método de equações simultâneas.

No caso do modelo para GR, têm-se $\mathrm{K}=2$ e $\mathrm{N}=2$, portanto: $2>(2-1)$, isso significa que a equação está sobreidentificada, o que permite a análise simultânea dessa equação.
Testando a equação do Ki, tem-se o exposto na Tabela $6 \boldsymbol{0}$.

No caso do modelo para Ki, têm-se $\mathrm{K}=6 \mathrm{e}$ $\mathrm{N}=2$, portanto: $6>(2-1)$; logo, essa equação, também, é sobreidentificada. Assim, os resultados são positivos para o uso das equações simultâneas. Contudo, ainda é necessário fazer o teste de simultaneidade para comprovar ou não tal relação e, assim, fazer as análises com os estimadores apropriados.

Para testar a simultaneidade entre GR e Ki, adotou-se o teste de especificação de Hausman, seguindo metodologia exposta em Gujarati (2006). O resultado está demonstrado na Tabela 70 .

Pelo teste de especificação de Hausman, os resíduos $\omega ́$ e $v$ não foram significativos, portanto, não se rejeita a hipótese nula de não simultaneidade, ou seja, GR e Ki não possuem uma relação simultânea. Tal resultado rejeita a hipótese 1 do trabalho. Logo, não se pode afirmar que haja uma inter-relação entre o GR e o custo da dívida das empresas brasileiras abertas, conforme possibilitavam as questões sobre a busca por melhores condições contratuais, entre elas o custo da dívida, por meio do GR póscontrato, de modo a atender às restrições contratuais impostas no período corrente para facilitar a obtenção de recursos futu-

Tabela 5 Condição de rank para teste de identificação do modelo de GR

\begin{tabular}{|c|c|c|c|c|c|c|c|c|c|c|c|c|c|c|}
\hline \multirow{2}{*}{ Equações } & \multicolumn{14}{|c|}{ Variáveis do Sistema } \\
\hline & GR & Ki & Tam & $\mathrm{CO}$ & Desemp & Idade & Cresc & Lev & Volat & LL & ADR & Smoo & Tang & Fcx \\
\hline $\operatorname{GR}\left(1^{\mathrm{a}}\right)$ & -1 & $\alpha_{1}$ & $\alpha_{2}$ & $\alpha_{3}$ & $\alpha_{4}$ & $\alpha_{5}$ & $\alpha_{6}$ & $\alpha_{7}$ & $\alpha_{8}$ & $\alpha_{9}$ & $\alpha_{10}$ & $\alpha_{11}$ & 0 & 0 \\
\hline $\operatorname{Ki}\left(2^{a}\right)$ & $\beta_{1}$ & -1 & $\beta_{2}$ & 0 & 0 & $\beta_{3}$ & 0 & $\beta_{7}$ & $\beta_{6}$ & 0 & 0 & 0 & $\beta_{4}$ & $\beta_{5}$ \\
\hline
\end{tabular}

Tabela 6 Condição de rank para teste de identificação do modelo de Ki

\begin{tabular}{|c|c|c|c|c|c|c|c|c|c|c|c|c|c|c|}
\hline \multirow{2}{*}{ Equações } & \multicolumn{14}{|c|}{ Variáveis do Sistema } \\
\hline & GR & Ki & Tam & $\mathrm{CO}$ & Desemp & Idade & Cresc & Lev & Volat & LL & ADR & Smoo & Tang & Fcx \\
\hline$G R\left(1^{a}\right)$ & -1 & $\alpha_{1}$ & $\alpha_{2}$ & $\alpha_{3}$ & $\alpha_{4}$ & $\alpha_{5}$ & $\alpha_{6}$ & $\alpha_{7}$ & $\alpha_{8}$ & $\alpha_{9}$ & $\alpha_{10}$ & $\alpha_{11}$ & 0 & 0 \\
\hline Ki $\left(2^{a}\right)$ & $\beta_{1}$ & -1 & $\beta_{2}$ & 0 & 0 & $\beta_{3}$ & 0 & $\beta_{7}$ & $\beta_{6}$ & 0 & 0 & 0 & $\beta_{4}$ & $\beta_{5}$ \\
\hline
\end{tabular}


Tabela 7 Teste de Simultaneidade

\begin{tabular}{|c|c|c|c|c|}
\hline \multicolumn{5}{|c|}{ Teste de Especificação de Hausman } \\
\hline \multirow{2}{*}{ Variáveis Explicativas } & \multicolumn{2}{|c|}{$\mathrm{GR} \times \mathrm{Ki}$} & \multicolumn{2}{|c|}{$\mathrm{Ki} \times \mathrm{GR}$} \\
\hline & Coeficiente & $\mathrm{t}$ & Coeficiente & $\mathbf{T}$ \\
\hline$\hat{K} i$ & 0,0015 & 0,55 & & \\
\hline$\hat{G} R$ & & & 5,1922 & $1,97^{* *}$ \\
\hline$\hat{\omega}$ & 0,0009 & 1,15 & & \\
\hline$\hat{v}$ & & & 0,3728 & 1,25 \\
\hline Tam & $-0,0384$ & $-3,35^{* * *}$ & $-0,0242$ & $-0,15$ \\
\hline $\mathrm{CO}$ & 0,000 & 1,45 & & \\
\hline Desemp & 0,0029 & 0,67 & & \\
\hline Idade & 0,0058 & 3,81 & 0,0139 & 0,39 \\
\hline Cresc & 0,0910 & $6,91^{* * *}$ & & \\
\hline Lev & 0,0123 & 0,50 & $-0,7940$ & $-2,96^{* * *}$ \\
\hline Volat & 0,0003 & 1,07 & 0,0049 & 0,53 \\
\hline Tang & & & $-0,4146$ & $-0,58$ \\
\hline $\mathrm{Fcx}$ & & & 0,2566 & $4,38^{* * *}$ \\
\hline $\mathrm{LL}$ & 0,0116 & $1,87^{*}$ & & \\
\hline ADR & 0,0264 & $1,84^{*}$ & & \\
\hline Smoo & $-0,0090$ & $-0,42$ & & \\
\hline Const. & 0,4783 & $3,58^{* * *}$ & 0,9668 & 0,63 \\
\hline $\mathrm{R}^{2}$ & \multicolumn{2}{|c|}{9,18} & \multicolumn{2}{|c|}{28,75} \\
\hline Estatística $F$ & \multicolumn{2}{|c|}{$5,61 * * *$} & \multicolumn{2}{|c|}{$7,57^{* * *}$} \\
\hline
\end{tabular}

***, **, *: Significância a 1\%, 5\% e 10\%

ros, como destacam Watts e Zimmerman (1990), Healy e Whalen (1999) e Lopes e Martins (2005). De modo geral, o teste de simultaneidade, para análise da inter-relação entre GR e o custo da dívida, pressupõe uma relação ilustrada no quadro A da figura a seguir. Contudo, apenas com esse teste não significa que as possibilidades de inter-relação entre as variáveis tenham sido eliminadas, pois a inter-relação pode ocorrer de modo iterativo ou sequencial, como destacado no quadro B da Figura 10.

Desse modo, os testes seguintes, com da- dos dispostos em painel, permitem estudar a inter-relação, como exposto no quadro B da figura anterior, sendo que, se as duas relações forem verificadas ( $a$ e b), ainda se pode dizer que há inter-relação entre as variáveis. Por outro lado, se apenas uma das relações forem significativas, tem-se, então, uma relação unidirecional entre GR e custo da dívida.

\subsection{Análise em Painel}

$\mathrm{Na}$ tentativa de identificar a inter-relação entre GR e Ki, foi feita uma análise com dados dispostos em painel sobre as equações 


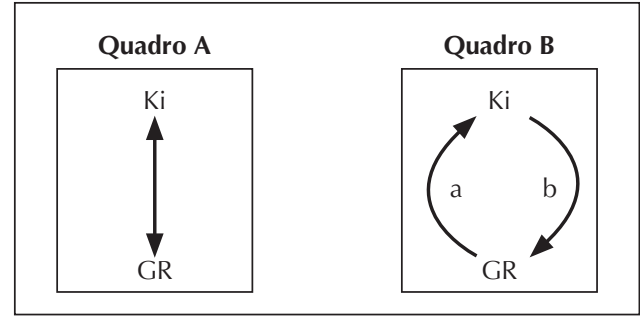

Figura 1 Inter-relação entre GR e Ki

(1) e (2), previamente desenvolvidas. Desse modo, na Tabela $8 \boldsymbol{\nabla}$, estão apresentados os resultados dos modelos com efeitos fixos e aleatórios, o teste de Hausman e o modelo com estimadores robustos na presença de heterocedasticidade e correlação serial, por meio da correção de Newey-West.

Primeiramente, foi feita a regressão da relação "a", exposta na figura anterior. O teste de Hausman indicou o uso de efeitos aleatórios. Contudo, cabe destacar que o teste de Hausman calcula a diferença entre os betas (coeficientes) da regressão por Efeitos Fixos ou Efeitos Aleatórios, ou seja: $b$ - $\beta$, respectivamente. Se essa diferença for estatisticamente significante (portanto, diferente de zero), o teste aponta para uso de Efeitos Fixos. Mas se a diferença não for estatisticamente significante, significa que $b \approx \beta$ e o teste aponta para Efeitos Aleatórios. Nesse caso, já que os coeficientes são próximos, com diferença não significativa, a análise pode ser feita com o modelo de Efeitos Fixos ou Efeitos Aleatórios, segundo Hill, Griffiths e Judge (2006, p. 346) e Maddala (2003, p. 264).

Assim, o resultado do modelo já corrigido

Tabela 8 Modelo corrigido para relação Ki x GR

\begin{tabular}{|c|c|c|c|c|}
\hline \multicolumn{5}{|c|}{ Ki x GR: Modelos Corrigidos } \\
\hline \multirow{2}{*}{ Variáveis Explicativas } & \multicolumn{2}{|c|}{ Efeitos Fixos } & \multicolumn{2}{|c|}{ Efeitos Aleatórios } \\
\hline & Coeficiente & z & Coeficiente & $\mathbf{Z}$ \\
\hline GR & 0,7065 & $2,17^{* *}$ & 1,0376 & $3,19 * * *$ \\
\hline Tam & $-0,0552$ & $-0,33$ & $-0,0789$ & $-1,11$ \\
\hline Idade & 0,0007 & 0,02 & 0,0127 & 1,01 \\
\hline Lev & $-0,6789$ & $-2,72^{* * *}$ & $-0,8772$ & $-3,08^{* * *}$ \\
\hline Volat & 0,0039 & 0,43 & 0,0048 & 0,97 \\
\hline Tang & $-0,2614$ & $-0,35$ & $-0,1252$ & $-0,67$ \\
\hline Fcx & 0,2591 & $4,40^{* * *}$ & 0,2577 & $3,94^{* * *}$ \\
\hline Const. & 1,4153 & 0,88 & 1,4593 & 1,49 \\
\hline $\mathrm{R}^{2}$ & \multicolumn{2}{|c|}{27,94} & \multicolumn{2}{|c|}{27,57} \\
\hline Estatística $F / X^{2}$ & \multicolumn{2}{|c|}{$8,10^{* * *}$} & \multicolumn{2}{|c|}{$58,79 * * *$} \\
\hline
\end{tabular}

***, **: Significância a 1\% e 5\% 
em relação à heterocedasticidade, correlação serial e multicolinearidade está apresentado na Tabela 8 .

Percebe-se que o coeficiente de GR foi significativo a $1 \%$ e a $5 \%$ nos modelos com efeitos aleatórios e efeitos fixos, respectivamente. Isso significa que a variação do GR das empresas exerce influência na variação do custo da dívida. A magnitude dos coeficientes gerados pelas regressões indica a importância da variável explicativa sobre a explicada. Portanto, quanto maior o coeficiente, maior o impacto ou a dependência. Nessa relação, Ki x GR, o coeficiente foi de 1,0376 e 0,7065 nos modelos de Efeitos Aleatórios e de Efeitos Fixos, respectivamente. Além disso, cabe destacar que a relação entre as duas variáveis foi positiva e significante (maior GR resulta em maior custo da dívida).

Dessa forma, e diante do resultado do teste de especificação de Hausman, resta verificar a relação "B”, a qual pressupõe o custo da dívida influenciando o GR. Assim, se essa relação for significativa, diz-se que há indícios de inter-relação entre as variáveis.

De modo semelhante à relação $\mathrm{A}$, seguem os resultados da regressão, na Tabela $9 \bullet$, em que GR é dependente e Ki é explicativa. Contudo, como o teste de Hausman indicou o uso de efeitos fixos, optou-se por apresentar apenas esse teste com a regressão já corrigida.

Quanto ao coeficiente do $\mathrm{Ki}$, apesar de ter sido positivo, como resultado da correlação de Spearman, ele não se apresentou estatisticamente significativo, indicando que as variações no custo da dívida não impactam nas variações do GR das empresas brasileiras abertas.

De modo geral, pelos resultados apresentados anteriormente, a possibilidade de inter-relação entre GR e custo da dívida das empresas brasileiras abertas, no período de
Tabela 9

Modelo corrigido para

a relação GR x Ki

\begin{tabular}{l|c|c}
\multirow{2}{*}{$\begin{array}{l}\text { Variáveis } \\
\text { Explicativas }\end{array}$} & \multicolumn{2}{|c}{$\begin{array}{c}\text { Modelo de Efeitos } \\
\text { Fixos Corrigido }\end{array}$} \\
\cline { 2 - 3 } & Coeficiente & $\mathbf{z}$ \\
\hline Ki & 0,0011 & 1,28 \\
\hline Tam & $-0,0384$ & $-3,36^{* * *}$ \\
\hline CO & 0,0000 & 1,46 \\
\hline Desemp & 0,0029 & 0,68 \\
\hline Idade & 0,0059 & $3,83^{* * *}$ \\
\hline Cresc & 0,0913 & $7,00^{* * *}$ \\
\hline Lev & $-0,0117$ & $-0,49$ \\
\hline Volat & 0,0003 & 1,11 \\
\hline LL & 0,0117 & $1,90^{*}$ \\
\hline ADR & 0,0264 & $1,84^{*}$ \\
\hline Smoo & $-0,0091$ & $-0,42$ \\
\hline Const. & 0,4785 & $3,58^{* * *}$ \\
\hline R ${ }^{2}$ & & 9,12 \\
\hline Estatística $F / X^{2}$ & & $6,07^{* * *}$ \\
\hline & & \\
\hline
\end{tabular}

***, **, *: Significância a 1\%, 5\% e 10\%

1996 a 2007, não foi verificada pelo teste de simultaneidade, nem pela análise de regressão com dados em painel, pois a relação "a" da figura 3 foi significante, mas a "b" não. Assim, constata-se que a relação entre as variáveis é unidirecional e se dá com a variação do gerenciamento de resultados no período corrente exercendo influencia, positivamente, na variação do custo da dívida, também do período corrente. Esse resultado permite rejeitar a hipótese 1 do trabalho, mas não rejeita a hipótese 2 .

Cabe ressaltar, ainda, que todos os testes anteriores foram feitos com a variável de gerenciamento de resultados e custo da dívida defasados, mas os testes não apresentaram resultados significativamente diferentes.

\section{CONSIDERAÇÕES FINAIS}

Com o suporte da teoria de agência e diante das premissas e pressupostos da litera- tura sobre gerenciamento de resultados, suas motivações e consequências, o objetivo deste 
trabalho foi contribuir com o conhecimento sobre a relação entre o custo de capital de terceiros e o gerenciamento de resultados contábeis, por meio do exame das empresas brasileiras abertas, no período de 1996 a 2007.

O trabalho utilizou como proxy do gerenciamento de resultados os accruals discricionários provenientes do resíduo do modelo de Kang e Sivaramakrishnan (1995), e o custo da dívida foi representado pela relação entre a despesa financeira e o endividamento total da empresa. Além disso, outras variáveis de controle foram especificadas.

Quanto aos resultados, os testes de correlação de Spearman e o teste não paramétrico U de Mann-Whitney indicaram uma relação positiva entre GR e custo da dívida. Em seguida, para testar a primeira hipótese do estudo, utilizou-se o teste de especificação de Hausman, na tentativa de identificar interrelação entre GR e custo da dívida mediante o uso de simultaneidade. Mas os resultados não foram, estatisticamente, significantes, não indicando a possibilidade de inter-relação entre as variáveis.

Contudo, ainda para testar o possível inter-relacionamento entre GR de resultados e custo da dívida, fez-se a análise de regressão com dados dispostos em painel, já que a interrelação entre as variáveis pode ser iterativa ou sequencial. Para isso, aplicou-se o teste de Multiplicador de Lagrange, indicando, para todos os modelos, que deveria ser testado o modelo de efeitos fixos e aleatórios, o que foi feito por meio do teste de Hausman. Pelos resultados da análise em painel, verificou-se que o custo da dívida é influenciado pelo gerenciamento de resultados, mas que o contrário não é verdadeiro. Esse resultado confirma o encontrado pelo teste de simultaneidade, ou seja, de que não há indícios de inter-relação entre GR e custo da dívida das empresas brasileiras abertas. Assim sendo, a hipótese 1 do trabalho foi rejeitada e as evidências indicaram uma relação unidirecional, em que o custo da dívida sofre influência do GR.
Além disso, os resultados das regressões em painel apontaram para uma relação positiva entre gerenciamento de resultados e custo da dívida. Verificou-se que o gerenciamento de resultados influencia o custo da dívida das companhias, de modo que maior GR tem como consequência maior custo da dívida. Esse resultado foi semelhante ao feito pelo índice de correlação de Spearman e pela análise de diferença de médias com o teste não paramétrico $U$ de Mann-Whitney. Tal resultado não permite rejeitar a hipótese 2 da pesquisa. A literatura, com base na teoria de agência, diz que existem incentivos para que agentes busquem interesses particulares, nem que isso ocasione a expropriação da riqueza do principal, o qual, consciente dessa possibilidade, exige retorno maior pelos recursos alocados em uma empresa, por exemplo. Portanto, as instituições financeiras, ao analisarem as demonstrações das empresas e identificarem gerenciamento de resultados, podem entendê-las como informações de baixa qualidade, elevando os riscos das fontes de financiamento, que podem cobrar taxas mais altas; consequentemente, maior o custo para a empresa, como destacam Leuz e Verrecchia (2005). Cabe ressaltar que essa justificativa é apenas especulativa, já que a pesquisa não possui caráter explicativo. Logo, um estudo minucioso em relação ao custo da dívida da empresa, acompanhando as variações das taxas dos diversos empréstimos, seria necessário e interessante como pesquisa futura.

Portanto, os resultados do estudo não indicaram que o custo da dívida motiva o gerenciamento de resultados que, por sua vez, seria feito pelas empresas com a intenção de melhorar seu custo da dívida. Mas os resultados apontaram para uma relação unidirecional em que o custo da dívida é influenciado positivamente pelo GR.

Por fim, cabe ressaltar que pesquisas futuras podem ser desenvolvidas aproveitando as limitações do presente estudo; como: exploração de outras metodologias para estudar as 
relações entre as variáveis; uso das despesas ativadas no cálculo do custo da dívida; consideração do risco de contraparte por meio da escala de rating, como utilizado por Vicente (2007). Ainda sobre os fatores que in- fluenciam o valor da variável custo da dívida, em função das características do mercado brasileiro, como taxas de crédito subsidiado inferiores as demais taxas, seria interessante controlá-los, o que não foi feito neste estudo

\section{Referências}

ABOODY, D.; HUGHES, J.; LIU, J. Earnings quality, insider trading, and cost of capital. Journal of Accounting Research, v. 43, n. 5, p. 651-673, dec. 2005.

ANDRADE, A.; ROSSETTI, J. P. Governança corporativa. fundamentos, desenvolvimento e tendências. 2. ed. São Paulo: Atlas, 2006.

BHARATH, S. T.; SUNDER, J.; SUNDER, S. V. Accounting quality and debt contracting. The Accounting Review, v. 83, n. 1, p. 1-28, jan. 2008.

BOUBAKRI, N.; GHOUMA, H. Managerial opportunism, cost of debt financing and regulation changes evidence from the Sarbanes-Oxley Act adoption. Working Paper. Disponível em: <http://papers.ssrn.com>. Acesso em: 2 out. 2008.

CALEGARI, M. J. The effect of tax accounting rules on capital structure and discretionary accruals. Journal of Accounting and Economics, v. 30, p. 1-31, 2000. CAMERON, A. C.; TRIVEDI, P. K. Microeconomics: methods and applications. New York: Cambridge University Press, 2005.

COELHO, A. C. D. Qualidade informacional e conservadorismo nos resultados contábeis publicados no Brasil. 2007. 240p. Tese (Doutorado em Controladoria e Contabilidade) - Faculdade de Economia, Administração e Contabilidade, Universidade de São Paulo, São Paulo. COLAUTO, R. D.; BEUREN, I. M. A Identificação de accruals no sistema de lucro contábil: o caso Parmalat Brasil. In: ENCONTRO NACIONAL DOS PROGRAMAS DE PÓS-GRADUAÇÃO EM ADMINSTRAÇÃO, 28, 2004, Curitiba-PR. Anais..., Curitiba: ANPAD, 2004.

DECHOW, P. M.; DICHEV, I. D. The quality of accruals and earnings: the role of accounting accruals estimation errors. The Accounting Review; v. 77, p. 35-59, 2002. ; SLOAN, R. G.; SWEENEY, A. P. Detecting earnings management. The Accounting Review, v. 70, n. 2, p. 193-225, abr. 1995.

DECOURT, R. F.; MARTINEWSKI, A. L.; PIETRO NETO, J. Existe gerenciamento de resultados nas empresas com ações negociadas na Bovespa? In: CONGRESSO USP DE CONTROLADORIA E CONTABILIDADE, 7, 2007, São Paulo. Anais..., São Paulo, 2007.

EASLEY, D.; O'HARA M. Information and the cost of capital. Working Paper. 2001. Disponível em: <http:// papers.ssrn.com>. Acesso em: 20 nov. 2007.

FIELDS, T. D.; LYS, T. Z.; VINCENT, L. Empirical research on accounting choice. Journal of Accounting and Economics, New York, v. 31, n. 1-3, p. 255-307, set. 2001.
FORMIGONI, H.; PAULO, E.; PEREIRA, C. A. Estudo sobre o gerenciamento de resultados contábeis pelas companhias abertas e fechadas brasileiras. In: ANPCONT, 1, 2007, Gramado. Anais..., Rio Grande do Sul: ANPCONT, 2007.

; ANTUNES, M. T. P.; PAULO, E. Diferença entre o lucro contábil e lucro tributável: uma análise sobre o gerenciamento de resultados contábeis e gerenciamento tributário nas companhias abertas brasileiras. In:

ANPCONT, 1, 2007, Gramado. Anais..., Rio Grande do Sul: ANPCONT, 2007.

FRANCIS, J. et al. The market pricing of earnings quality. Draft. October 2002. Disponível em: <http://www. ebr360.org>. Acesso em: 20 nov. 2007.

. Costs of equity and earnings attributes. The Accounting Review, v. 79, n. 4, p. 967-1010, out. 2004. . The market pricing of accrual quality. Journal of Accounting and Economics, v. 39, p. 295-327, mar. 2005. FRANCIS, J. R.; KHURANA, I. K.; PEREIRA, R. Diclosure incentives and effects on cost of capital around the world. The Accounting Review, v. 80, n. 4, p.11251262, out. 2005.

GUJARATI, D. N. Econometria Básica. Tradução: Ernesto Yoshida. São Paulo: Pearson Makron Books, 2000.

GU, Z.; LEE, C. J.; ROSETT, J. G. What determines the variability of accounting accruals? Review of Quantitative Finance and Accounting, v. 24, p. 313-334, 2005.

GUAY, W. R.; KOTHARI, S. P.; WATTS, R. A marketbased evaluation of discretionary accrual model. Journal of Accounting Research, v. 34, supl., p. 85-105, 1996.

HANSEN, G. A. Bias and measurement error in discretionary accrual models. Working Paper Series. nov. 1999. Social Science Research Network, 1999. Disponível em: <http://papers.ssrn.com/sol3/papers.cfm?abstract_ $\mathrm{id}=192748>$. Acesso em: 15 abr. 2008.

HASSABELNABY, H. R.; MOSEBACH, M.;

WHISENANT, S. The effect of technical default cost on discretionary accounting decisions. Working Paper Series. 2005. Disponível em: <http://papers.ssrn.com/ sol3/papers.cfm?abstract_id $=660802>$. Acesso em: 29 set. 2008.

HEALY, P. M.; WAHLEN, J. M. A review of the earnings management literature and its implications for standard setting. Accounting Horizons, v. 13, p. 365-383, 1999.

HENDRINKSEN, E. S.; VAN BREDA, M. F. Teoria da Contabilidade. Tradução: Antonio Zoratto Sanvicente. São Paulo: Atlas, 1999. 
HILL, R. C.; GRIFFITHS, W. E.; JUDGE, G. G. Econometria. Tradução: Alfredo Alvers de Farias. 2 ed. Sao Paulo: Saraiva. 2006.

HOLTHAUSEN, R. W.; LEFTWICH, R. W. The economic consequences of accounting choice: implications of costly contracting and monitoring. Jounal of Accounting and Economics, North-Holland, v. 5, p. 77-117, jun. 1983.

JENSEN, M.; MECKLING, W. H. Theory of the firm: managerial behavior, agency costs and ownership structure. Journal of Financial Economics, v. 3, n. 4, p. 305-360, out. 1976.

KANG, S.; SIVARAMAKRISHNAN, K. Issues in testing earnings management and an instrumental variable approach. Journal of Accounting Research, Oxford. v. 33, n. 2, p. 353-367, autumn 1995.

LEUZ, C.; NANDA, D.; WYSOCKI, P. Earnings management and investor protection: an international comparison. Journal of Financial Economics. v. 69, p. 505-527, 2003.

; VERRECCHIA, R. E. Firms' capital allocation choices, information quality, and the cost of capital. In: Social Science Research Network. Working Paper. 2005. Disponível em: <http://papers.ssrn.com/sol3/papers. cfm?abstract_id=495363 > . Acesso em: 19 fev. 2008. LIMA, G. A. S F. Utilização da teoria da divulgação para avaliação da relação do nível de disclosure com o custo da dívida das empresas brasileiras. 2007. 108p. Tese (Doutorado em Controladoria e Contabilidade) Faculdade de Economia, Administração e Contabilidade, Universidade de São Paulo, São Paulo.

LOPES, A. B.; MARTINS, E. Teoria da Contabilidade. São Paulo: Atlas, 2005.

MADDALA, G. S. Introdução à Econometria. Tradução Leonardo Weller. Rio de Janeiro: LTC, 2003.

MANSI, S. A.; MAXWELL, W. F.; MILLER, D. P. Analyst forecast characteristics and the cost of debt. Working Paper. 2007. Disponível em: <http://papers.ssrn.com>. Acesso em: 19 fev. 2008.

MARTINEZ, A. L. Gerenciamento dos resultados contábeis: estudo empírico das companhias abertas brasileiras. 2001. 153 f. Tese (Doutorado em Ciências Contábeis) - Faculdade de Economia, Administração e Contabilidade, Universidade de São Paulo, São Paulo. ; FARIA, M. P. Emissão de debêntures e earnings management no Brasil. In: ENCONTRO NACIONAL DOS PROGRAMAS DE PÓS-GRADUAÇÃO EM ADMINSTRAÇÃO, 31, 2007, Rio de Janeiro-RJ. Anais..., Curitiba: ANPAD, 2007.

McNICHOLS, M. F. Research design issues in earnings management studies. Journal of Accounting and Public Policy, v. 19, p. 313-345, 2003.

PAULO, E. Manipulação das informações contábeis: uma análise teórica e empírica sobre os modelos operacionais de detecção de gerenciamento de resultados. 2007. 269f. Tese (Doutorado em Contabilidade) - Faculdade de Economia, Administração e Contabilidade, Universidade de São Paulo, São Paulo.
; MARTINS, E. Análise das informações contábeis nas companhias abertas. In: ENCONTRO NACIONAL DOS PROGRAMAS DE PÓSGRADUAÇÃO EM ADMINSTRAÇÃO, 31, 2007, Rio de Janeiro-RJ. Anais..., Curitiba: ANPAD, 2007.

; LEME, J. Gerenciamento de resultados contábeis e o anúncio dos resultados contábeis pelas companhias abertas brasileiras. In: ENCONTRO NACIONAL DOS PROGRAMAS DE PÓS-GRADUAÇÃO EM ADMINSTRAÇÃO, 31, 2007, Rio de Janeiro-RJ. Anais..., Curitiba: ANPAD, 2007.

PAULO, E. et al. A influência da cobertura das empresas de rating sobre o gerenciamento de resultados das companhias abertas brasileiras. In: CONGRESSO USP DE CONTROLADORIA E CONTABILIDADE, 8, 2008, São Paulo. Anais..., São Paulo, 2008.

PINDYNCK, R. S.; RUBINFELD, D. L. Econometria: modelos e previsões. 4. ed. Rio de Janeiro: Elsevier, 2004. RICHARDSON, V. J. Information asymmetry and earnings management: some evidence. Review of Quantitative Finance and Accounting, v. 15, p. 325-347, 2000.

SCHIPPER, K. Commentary: Earnings Management. Accounting Horizons, v. 3, p. 91-102, dec. 1989.

SENGUPTA, P. Corporate disclosure quality and the cost of debt. The Accounting Review, v. 73, n. 4, p. 459-474, out. 1998.

SUBRAMANYAN, K. R. The pricing of discretionary accruals. Journal of Accounting and Economics, v. 22, p. 249-281, 1996.

SUNDER, S. Theory of accounting and control. Ohio: South-Western Publishing, 1997.

TEOH, S. H.; WELCH, I.; WONG, T. J. Earnings management and the long run underperformance of seasoned public offerings. Journal of Financial Economics, v. 50, p. 63-99, 1998.

THOMAS, J.; ZHANG, X. Identifying unexpected accruals: a comparison of current approaches. Journal of Accounting and Public Policy, v. 19, p. 347-376, 2000.

VALLE, M. R. A estrutura de capital das empresas brasileiras num ambiente de altas taxas de juros e na presença de fontes diferenciadas de financiamento. 2007. 104 p. Tese (Concurso de Livre-docência-Departamento de Contabilidade) - Faculdade de Economia,

Administração e Contabilidade, Universidade de São Paulo, São Paulo.

VERRECCHIA, R. E. Discretionary disclosure. Journal of Accounting and. Economics, Amsterdam, v. 5, n. 3, p. 179-194, dez. 1983.

VICENTE, A. T. R. S. Requisitos de capital e solvência II: uma aplicação ao seguro de automóvel. 2007. 91 f. Dissertação (Mestrado em Ciências Actuariais) Instituto Superior de Economia e Gestão, Universidade Técnica de Lisboa, Lisboa.

WATTS, R. L.; ZIMMERMAN, J. L. Positive accounting theory: a ten year perspective. The Accounting Review, v. 65, n. 1, p. 131-156, jan. 1990. 


\section{Apêndice}

As Tabelas seguintes compreendem outros testes realizados, com o intuito de confirmar os resultados expostos ao longo do trabalho.

Como dito ao longo do artigo, diante da identificação de relação simultânea entre as variáveis, o estimador mais eficiente seria o MQ2E. Apesar de o teste de especificação de Hausman não ter indicado presença de simultaneidade, optou-se, assim mesmo, por testar os modelos por meio de MQ2E, de modo a confirmar o resultado do teste de simultaneidade, como pode ser observado nas Tabelas 100 e 110 .

No artigo, os modelos foram apresentados mediante correção de Newey-West, a qual, segundo Cameron e Trivedi (2005), é mais eficiente que a correção por clusters, embora essa, também, seja considerada apropriada para dados em painel. Assim, as Tabelas 12 e $13 \oslash$ compreendem as regressões dos modelos em painel com correção por clusters.
Tabela 11 MQ2E para modelo de Ki

\begin{tabular}{c|c|c|c|c}
\multirow{2}{*}{$\begin{array}{c}\text { Variáveis } \\
\text { Explicativas }\end{array}$} & \multicolumn{2}{|c|}{ Efeitos Fixos } & \multicolumn{2}{c}{ Efeitos Aleatórios } \\
\cline { 2 - 5 } & Coeficiente & $\mathbf{z}$ & $\begin{array}{c}\text { Coefi- } \\
\text { ciente }\end{array}$ & $\mathbf{z}$ \\
\hline GR & 10,1557 & $5,02^{* * *}$ & 14,3067 & $6,41^{* * *}$ \\
\hline Tam & $-0,0102$ & $-0,05$ & $-0,0757$ & $-0,92$ \\
\hline Idade & 0,0300 & 1,00 & 0,0061 & 0,48 \\
\hline Lev & $-0,9213$ & $-1,93^{* *}$ & $-1,149$ & $-2,45^{* * *}$ \\
\hline Volat & 0,0059 & 0,85 & 0,0052 & $3,24^{* * *}$ \\
\hline Tang & $-0,5841$ & $-0,80$ & $-0,0029$ & $-0,01$ \\
\hline Fcx & 0,2540 & $16,69 * * *$ & 0,2499 & $16,01^{* * *}$ \\
\hline Const. & 0,4705 & 0,19 & $-1,4597$ & $-1,20$ \\
\hline $\mathbf{R}^{2}$ & \multicolumn{2}{|c|}{11,39} & \multicolumn{2}{c}{13,04} \\
\hline Estatística $F$ & $47,43^{* * *}$ & \multicolumn{2}{c}{$54,24^{* * *}$} \\
\hline
\end{tabular}

***, **: Significância a 1\% e 5\%

Pela Tabela 12, percebe-se que o custo da dívida não apresentou significância em relação à variável de gerenciamento de resultados. Cabe destacar que o modelo apresentou

Tabela 10 MQ2E para modelo de GR

\begin{tabular}{l|c|c|c|c}
\multirow{2}{*}{ Variáveis Explicativas } & \multicolumn{2}{|c}{ Efeitos Fixos } & \multicolumn{2}{c}{ Efeitos Aleatórios } \\
\cline { 2 - 5 } & Coeficiente & Z & 0,0011 & \multicolumn{2}{c}{ Z } \\
\hline \multirow{2}{*}{ Kam } & 0,0015 & 0,58 & $-0,0168$ & $-5,85^{* * *}$ \\
\hline CO & $-0,0384$ & $-4,03^{* * *}$ & 0,0000 & $1,77^{*}$ \\
\hline Desemp & 0,0000 & 1,73 & 0,0020 & 1,24 \\
\hline Idade & 0,0029 & $1,77^{*}$ & 0,0014 & $3,41^{* * *}$ \\
\hline Cresc & 0,0059 & $4,58^{* * *}$ & 0,0813 & $9,77^{* * *}$ \\
\hline Lev & 0,0910 & $10,33^{* * *}$ & $-0,0197$ & $-1,02$ \\
\hline Volat & $-0,0123$ & $-0,57$ & 0,0001 & 0,77 \\
\hline LL & 0,0003 & 0,85 & 0,0185 & $2,80^{* * *}$ \\
\hline ADR & 0,0116 & 1,66 & 0,0256 & $1,67^{*}$ \\
\hline Smoo & 0,0264 & 1,17 & $-0,0024$ & $-0,12$ \\
\hline Const. & $-0,0090$ & $-0,46$ & 0,2679 & $6,64^{* * *}$ \\
\hline R & 0,4783 & $4,14^{* * *}$ & & 13,87 \\
\hline Estatística $F$ & & 9,19 & & $13,38^{* * *}$
\end{tabular}


um $\mathrm{R}^{2}$ de $9,12 \%$, indicando que o modelo não está tão bem ajustado, já que, segundo Pindynck e Rubinfeld (2004, p. 100), esta estatística informa a qualidade do ajusta- mento do modelo e compara a "validade dos resultados de regressão com as especificações alternativas de variáveis explanatórias no modelo".

Tabela 12 Modelo de Efeitos Fixos com correção por clusters para o modelo GR x Ki

\begin{tabular}{l|c|c}
\multirow{2}{*}{ Variáveis Explicativas } & \multicolumn{2}{|c}{ GR Correção por Cluster } \\
\cline { 2 - 3 } & Coeficiente & z \\
\hline \multirow{2}{*}{ Tam } & 0,0011 & 1,28 \\
\hline CO & $-0,0384$ & $-2,90^{* * *}$ \\
\hline Desemp & 0,0000 & $2,25^{* *}$ \\
\hline Idade & 0,0029 & 0,65 \\
\hline Cresc & 0,0059 & $2,69^{* * *}$ \\
\hline Lev & 0,0913 & $6,99^{* * *}$ \\
\hline Volat & $-0,0117$ & $-0,74$ \\
\hline LL & 0,0003 & 0,93 \\
\hline ADR & 0,0117 & $1,85^{*}$ \\
\hline Smoo & 0,0264 & 1,53 \\
\hline Const. & $-0,0091$ & -0.42 \\
\hline R & 0,4785 & $3,21^{* * *}$ \\
\hline Estatística $F / X^{2}$ & & \\
\hline
\end{tabular}

***, **, *: Significância a 1\%, 5\% e 10\%

Tabela 13 Modelos de Efeitos Fixos e Efeitos Aleatórios com correção por clusters para o modelo Ki x GR

\begin{tabular}{l|c|c|c|c}
\multirow{2}{*}{ Variáveis Explicativas } & \multicolumn{2}{|c|}{ Cluster: Efeitos Fixos } & \multicolumn{2}{c}{ Cluster: Efeitos Aleatórios } \\
\cline { 2 - 5 } & Coeficiente & $\mathbf{z}$ & Coeficiente & $\mathbf{z}$ \\
\hline GR & 0,7065 & $2,72^{* * *}$ & 1,0376 & $3,43^{* * *}$ \\
\hline Tam & $-0,0552$ & $-0,28$ & $-0,0789$ & $-1,11$ \\
\hline Idade & 0,0007 & 0,02 & 0,0127 & 1,26 \\
\hline Lev & $-0,6789$ & $-2,28^{* *}$ & $-0,8772$ & $-2,84^{* * *}$ \\
\hline Volat & 0,0039 & $-0,40$ & 0,0048 & $3,23^{* * *}$ \\
\hline Tang & $-0,2614$ & $-0,35$ & $-0,1252$ & $-0,72$ \\
\hline Fcx & 0,2591 & $3,82^{* * *}$ & 0,2577 & $3,70^{* * *}$ \\
\hline Const. & 1,4153 & 0,76 & 1,4593 & 1,54 \\
\hline$R^{2}$ & \multicolumn{4}{|c|}{27,94} \\
\hline Estatística $F / x^{2}$ & $6,08^{* * *}$ & & 27,57 \\
\hline
\end{tabular}

***, **: Significância a 1\% e 5\% 